
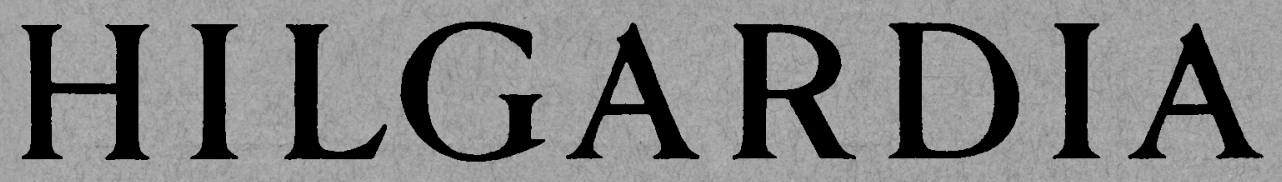

A Journal of Agricultural Science Published by the California Agricultural Experiment Station

\title{
THE EFFECT OF RICE CULTURE ON A NONSALINE SODIC SOIL OF THE FRESNO SERIES
}

ROY OVERSTREET

and

R. K. SCHULZ 
Four experimental plots were laid out in order to study the effect of rice culture on a nonsaline sodic soil of the Fresno series. The plots were situated near Traver, California, on land which had failed to produce an economical stand of cotton.

Good yields of rice were obtained on three of the plots and, on the basis of greenhouse tests, a general improvement in productivity as a result of the rice culture was noted. This increase in productivity, however, was not indicated in chemical tests made on the soils before and after rice.

It is concluded that rice culture serves as an efficient means of reclaiming this type of soil. It is concluded further that the accepted chemical methods for assessing the productivity of saltaffected soils may prove inadequate in important instances. 


\section{H I L G A R D I A}

A Journal of Agricultural Science Published by

the California Agricultural Experiment Station

\section{THE EFFECT OF RICE CULTURE ON A NONSALINE SODIC SOIL OF THE FRESNO SERIES ${ }^{1}$ \\ ROY OVERSTREET ${ }^{2}$ and R. K. SCHULZ}

\section{INTRODUCTION}

A NUMBER of leaching experiments, conducted in the laboratory and in the field (Overstreet et al., 1955) ${ }^{4}$, have demonstrated that hydrolysis may be effective in the removal of exchangeable sodium from sodic soils. ${ }^{5}$ For calcareous sodic soils, the hydrolysis process can be described by means of the reaction:

$$
2 \mathrm{Na}(\mathrm{ad})+\mathrm{H}_{2} \mathrm{O}+\mathrm{CaCO}_{3}-\mathrm{Ca}(\mathrm{ad})+2 \mathrm{Na}^{+}+\mathrm{HCO}_{3}^{-}+\mathrm{OH}^{-}
$$

where the suffix $(a d)$ refers to the adsorbed state.

In order to bring the hydrolysis reaction to completion, continuous removal of the soluble ion products is required. Similarly, for the process to be effective in reclamation, a certain amount of leaching of the soil profile is essential. This point has been given particular emphasis by Kelley (1951).

However, with fine-textured sodic soils, the attainment of the necessary leaching may be extremely slow. In work to be reported later with a sodic soil of the Hacienda series, the authors found that actual ponding of the land for periods of six to twelve months was required to bring about significant leaching. Also, the ponding procedure proved generally more effective than the growth of plants under moist conditions.

\footnotetext{
${ }^{1}$ Submitted for publication June 5, 1957.

${ }^{2}$ Professor of Soil Chemistry, Department Soils and Plant Nutrition and Soil Chemist in the Experiment Station, Berkeley.

${ }^{3}$ Assistant Specialist in the Experiment Station, Berkeley.

${ }^{4}$ See Literature Cited for citations referred to in text by author and date.

${ }^{5}$ The following nomenclature has been adopted in the present article and will be used by the authors hereafter:

Sodic soil-soil that contains sufficient exchangeable sodium to interfere with the growth of most erop plants. For purposes of definition, soil for which the exchangeable sodium percentage is 15 or more.

Saline soil-Soil that contains sufficient soluble salt to interfere with the growth of most crop plants. For purpose of definition, soil for which the conductivity of the saturation extract is 4 or more millimhos per $\mathrm{cm}$ at $25^{\circ} \mathrm{C}$.

Salt-affected soil-soil that has been adversely modified for the growth of most crop plants by the presence or action of soluble salts. The term includes soil having an excess of soluble salts, or an excess of exchangeable sodium, or both.

The above usage was recommended in October, 1956, by a nomenclature committee appointed by the Board of Collaborators of the U. S. Salinity Laboratory, Riverside, California.
} 
In line with the practice of ponding, one's attention is naturally drawn to rice culture, which in California involves an inundation of the land for approximately five months. In soils where the effects of salts are not severe enough to prevent its growth, the production of rice provides an economical use of the land during the period of leaching.

The commercial production of rice was initiated in California in 1912. Since then individual farmers from time to time have advocated the culture of rice as an aid in the reclamation of salt-affected soils. In recent years, the efforts of Lyle B. Oliver in Tulare County, California, are notable.

Mr. Oliver has systematized the use of rice culture for the reclamation of lands of the Fresno series. According to his procedure, the land is at first carefully leveled. Following this, rice is grown for three seasons. Very often crop production in the first year may be very poor. However, marked improvement in production is usually noted in the second and third seasons. $\Lambda$ fter the period of rice culture, the land is put into cotton and other commercial crops. By this procedure, substantial acreages have been brought into production in the vicinity of Traver, California.

In the present research, the chemical changes occurring during one of these reclamation attempts have been studied. The work deals with a nonsaline sodic soil of the Fresno series which would not support an economical crop of cotton.

\section{SOIL CHARACTERISTICS}

The area studied is situated about $31 / 2$ miles east of Traver, California, on the Lyle B. Oliver farm. This piece of land, consisting of approximately 600 acres, had grown a very unsuccessful crop of cotton during the 1953 season. Thus it was possible to select field plots on the basis of the variation in stand of cotton prior to the initiation of the rice culture.

The soil of the area has been classified as Fresno fine sandy loam. Approximately 25,000 acres of the Fresno series have been mapped in Tulare County. Some idea of the chemical nature of the soil can be obtained from Table 1 which corresponds to a somewhat representative profile.

It will be noted that the soil of this particular profile is essentially nonsaline. This is generally true of the whole area except for occasional spots where the conductivity of the saturation extract may be as high as 8 or 9 millimhos per $\mathrm{cm}$. The free salt is predominantly sodium bicarbonate; however, appreciable fractions of sodium chloride and sodium sulfate are present.

The soil is calcareous, but not excessively so. The insoluble carbonates, ealculated as per cent $\mathrm{CaCO}_{3}$, vary between 0.3 and 1.0 per cent.

The cation exchange capacity at the location represented by Table 1 is about 5.7 milliequivalents per 100 grams. In some parts of the area, the cation exchange capacity may reach a value of 10 m.e. per 100 grams, but by and large it is somewhat less than 10 .

As may be seen from the table, the exchangeable sodium percentage, as determined by the methods adopted, is quite high. In general there is no consistent variation of the exchangeable sodium percentage with depth. A description of the methods follows. 
TABLE 1

ANALYSIS OF FRESNO FINE SANDY LOAM FROM L. B. OLIVER FARM. ALL SOIL ANALYSES ARE ON THE BASIS OF THE OVEN-DRY SOIL $\left(105^{\circ} \mathrm{C}\right)$

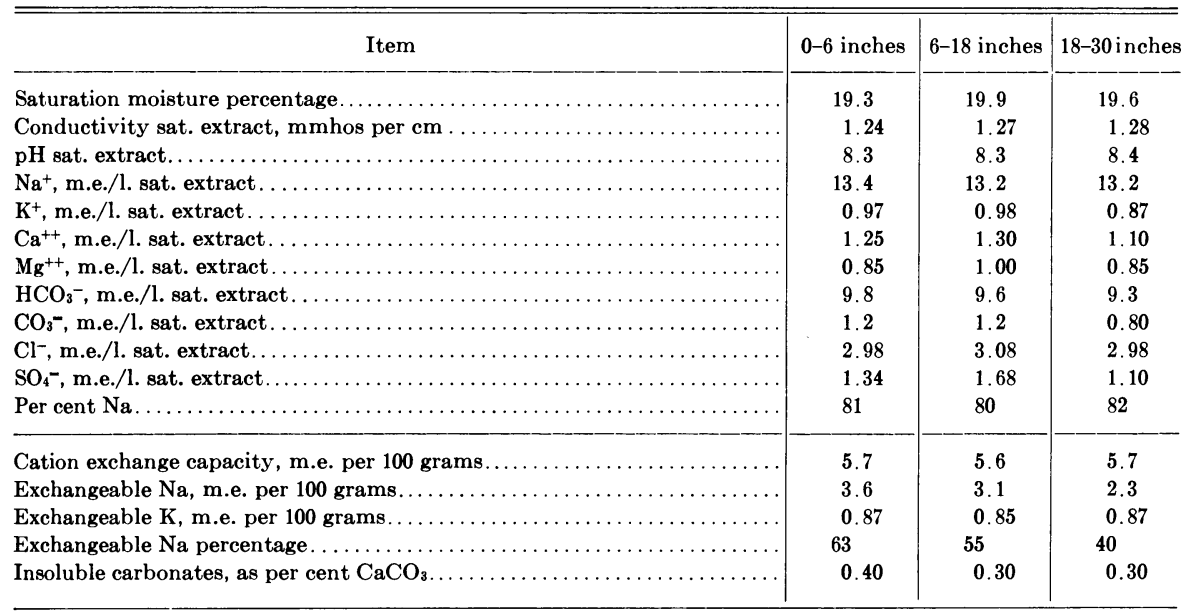

Hardpan at depth of 40 inches.

In the present research it has been assumed that the water-soluble ions are contained in the saturation water extract of the soil. Also, it has been assumed that the exchangeable plus soluble $\mathrm{Na}$ and $\mathrm{K}$ are contained in the ammonium acetate extract of the sample. The ammonium acetate extract was obtained by digestion of the soil at $70^{\circ} \mathrm{C}$ for two hours with an excess of neutral $1 \mathrm{~N} \mathrm{NH}_{4}$ Ac followed by leaching of the sample with this reagent at room temperature. The exchangeable $\mathrm{Na}$ and $\mathrm{K}$ were calculated as the difference between the $\mathrm{NH}_{4} \mathrm{Ac}$ extractable and water-soluble values.

The cation exchange capacity was determined on the sample used for the $\mathrm{NH}_{4} \mathrm{Ac}$ extraction. The excess $\mathrm{NH}_{4} \mathrm{Ac}$ was removed from the sample by leaching with neutral methyl alcohol. Following this, a water suspension of the soil was treated with $\mathrm{MgO}$ in a Kjeldahl flask and the adsorbed $\mathrm{NH}_{3}$ was distilled over into standard acid. The amount of $\mathrm{NH}_{3}$ distilled over was assumed to be equivalent to the cation exchange capacity.

A point of considerable chemical interest is the fact that the exchangeable sodium percentage, calculated from the values obtained for the exchangeable $\mathrm{Na}$ and the cation exchange capacity, occasionally may exceed 100 per cent in this area. Possible reasons for this discrepancy will be presented in a later section.

As is characteristic of the Fresno series, the soil of this area possesses a hardpan. The depth to the hardpan varies between 30 and 40 inches. Accurate information concerning the permeability of the hardpan to water 
is not available. However, approximately six acre feet of water are required during the first season of rice, and in ensuing seasons the amount of water necessary markedly increases, presumably as a result of increased permeability of the hardpan. After three seasons, the cost of water becomes an important economic consideration in the production of rice on this land.

The water used for flooding the land was obtained from a well close by the area. An analysis of water from the well is presented in Table 2.

TABLE 2

ANALYSIS OF WELL WATER USED FOR OLIVER RICE CULTURE $(\mathrm{pH}=7.6 ;$ conductivity $=0.49 \mathrm{~m}$. mhos per $\mathrm{cm})$

\begin{tabular}{|c|c|c|}
\hline Constituent & ppm & m.e. per liter \\
\hline $\mathrm{Ca}^{++}$. & 45 & 2.2 \\
\hline $\mathbf{M g}^{++} \ldots \ldots \ldots \ldots \ldots \ldots \ldots \ldots \ldots \ldots \ldots \ldots$ & 15 & 1.3 \\
\hline $\mathrm{Na}^{+} \ldots \ldots \ldots \ldots \ldots \ldots \ldots \ldots \ldots \ldots$ & 35 & 1.4 \\
\hline $\mathrm{HCO}_{3}{ }^{-} \ldots \ldots \ldots \ldots \ldots \ldots \ldots \ldots \ldots \ldots$ & 200 & 3.3 \\
\hline $\mathrm{CO}_{3}{ }^{-}$. & $\mathbf{T}$ & $\mathbf{T}$ \\
\hline $\mathrm{Cl}^{-}$. & 45 & 1.2 \\
\hline $\mathrm{SO}_{4}{ }^{-}$. & $\mathbf{5}$ & 0.1 \\
\hline Boron $\ldots \ldots \ldots \ldots \ldots \ldots \ldots \ldots \ldots$ & 0.00 & 0.0 \\
\hline
\end{tabular}

Sodium percentage $=29$

As may be seen from the table, the water is relatively low in salt. Also, it is boron-free and the sodium percentage is 29. According to all present schemes of classification, this would be considered good irrigation water.

\section{EXPERIMENTS}

In the fall of 1953, four plots were laid out at positions of varying stands of cotton. Plot number 1 was laid out in a region where a fair growth of cotton had occurred during the 1953 season. Plot number 2 was laid out at a position where a poor stand of cotton was in evidence. Plot number 3 corresponded to very nearly no growth of cotton and plot number 4 to no growth at all. Each plot was circular and 0.01 acre in area. In each case, the center of the plot was marked by a redwood post. Also the centers of the plots could be located by triangulation from fixed stations along a road bordering the area. The appearance of the plots in November, 1953, is shown in Figure 1.

At the time the plots were laid out, they were sampled to a depth of 30 inches. Large 200 pound samples were taken of the 0-6 inch level and approximately 20 pound samples were taken of the 6-18 inch and 18-30 inch levels. In each case, a composite of many small samples, taken at random over the 0.01 acre plot, was made for the 0-6 inch level. Samples of the lower levels were composites of soil taken from four symmetrically located borings with the barrel auger. The same sampling procedure was followed later on after the crop of rice had been taken off.

The large samples of the $0-6$ inch level were taken in order to permit greenhouse tests on the surface soil before and after rice culture.

In April, 1954, the land was prepared for rice and the area was flooded 
during the first part of May. On May 15, 1954, rice of the Caloro variety was planted by air. When the rice plants were established, the field was fertilized by air with $\left(\mathrm{NH}_{4}\right)_{2} \mathrm{SO}_{4}$ at the rate of 250 pounds per acre.

The growth of rice on the plots was recorded by means of photographs taken during the summer and fall of 1954. Initially, a good stand of rice was obtained on all of the plots. However, the plants on plot number 4 rapidly died off and after a few weeks none was in evidence. The condition of the crop on September 22, 1954, shortly before the water was drained off the land is shown in Figure 2.

The rice was harvested in the early part of October, 1954, and the plots were sampled for the second time.

The soil samples, taken before and after rice culture, were analyzed chemically. By far the greatest chemical changes were noted in the surface samples. Indeed, the differences noted in the lower depths were probably not significant because of much larger variability in sampling. For these reasons, the analyses of the surface samples only are presented here. The chemical data for the $0-6$ inch samples, before and after rice culture, are presented in Tables 3 to 6 .

As is indicated by the tables, the cation exchange capacity was determined in three ways; that is, by the $\mathrm{NH}_{4} \mathrm{Ac}$, the NaAc, and the Ba methods.

The ammonium acetate method, which was described earlier, may be subject to error in calcareous soils. This is due to the fact that calcium and magnesium carbonates dissolve to a fair extent in the $1 \mathrm{~N} \mathrm{NH}_{4} \mathrm{Ac}$ reagent. When this occurs, the exchange complex of the soil may not be completely saturated with $\mathrm{NH}_{4}{ }^{+}$ion even after prolonged leaching and a low value for the cation exchange capacity may result. Also, the ammonium acetate method may give low values in the case of many salt-affected soils that fix ammonium and potassium ions in nonexchangeable forms.

The sodium acetate method has been proposed by Bower, Reitemeier, and Fireman (1952) for calcareous soils. In brief it consists in saturating the exchange complex of the soil with $\mathrm{Na}^{+}$by leaching with $1 \mathrm{~N} \mathrm{NaAc}$ at $\mathrm{pH} 8$. Following this, the excess NaAc is removed with methyl alcohol and the adsorbed $\mathrm{Na}^{+}$is extracted with $1 \mathrm{~N} \mathrm{NH}_{4} \mathrm{Ac}$ and determined by means of the flame spectrophotometer. The method has the advantage that calcium and magnesium carbonates are only very slightly soluble in $\mathrm{NaAc}$ at $\mathrm{pH} 8$. Low values for the cation exchange capacity may be obtained by this method with soils that fix sodium in the nonexchangeable form (Overstreet et al., 1951).

The barium method for the determination of cation exchange capacity has been introduced by Schoonover (1955). It is a rapid method that consists in saturating the exchange complex of the soil with $\mathrm{Ba}^{++}$by leaching with neutral $1 \mathrm{~N} \mathrm{BaC1}_{2}$. Next, the excess $\mathrm{BaCl}_{2}$ is removed by leaching the soil with water. The $\mathrm{Ba}^{++}$saturated soil is then shaken with standard CaSO, solution and filtered. The amount of calcium disappearing from the standard $\mathrm{CaSO}_{4}$ solution is taken as a measure of the exchange capacity.

Included also in the tables are the "gypsum requirement" values for the soils expressed as milliequivalents per 100 grams of oven-dry soil. The gypsum requirement test has been proposed by Schoonover (1952). For this 
test, a small amount of soil is shaken with saturated $\mathrm{CaSO}_{4}$ solution and then filtered. The reduction in the amount of alkaline earth ions $\left(\mathrm{Ca}^{++}\right.$and $\mathrm{Mg}^{++}$) produced in the original $\mathrm{CaSO}_{4}$ solution is taken as being equivalent to the gypsum requirement value. Presumably it is also equivalent to the amount of exchangeable $\mathrm{Na}$ present in the soil.

In the spring of 1955 , greenhouse tests were run on the surface samples of soils from the plots taken before and after rice culture. For the purpose of the growth test, 42 pounds of the soil were placed in a 3-gallon can. The soil was then planted to bush beans - a plant considered rather sensitive to salt and to high amounts of exchangeable sodium. The growth tests were run in triplicate, and eight weeks from the time of planting the average fresh weights of the plants were as follows for the four plots before and after rice culture: plot number 1, $55.6 \mathrm{gms}$ and $47.6 \mathrm{gms}$; plot number 2, $20.1 \mathrm{gms}$ and $97.9 \mathrm{gms}$; plot number $3,3.6 \mathrm{gms}$ and $55.6 \mathrm{gms}$; and plot number 4 , $1.7 \mathrm{gms}$ and $27.3 \mathrm{gms}$. The general appearance of the bean plants, eight weeks after planting, is shown in the photographs of Figure 3.

The tract of land containing the plots was again planted to rice in the 1955 season. The progress of the crop was again recorded photographically. No marked changes in the stand of rice were observed, compared with the first season, except in the case of plot number 4 . Plot number 4 showed zero yield of rice in the 1954 season. However, in the 1955 season this plot had an appreciable stand of rice. This fact is illustrated in Figure 4 which is a photograph of plot number 4 taken on August 12, 1955.

The general area of the Oliver plots was allowed to lie fallow during the 1956 season. It was to be planted to barley late in the fall of 1956 and to cotton during the 1957 season.

\section{DISCUSSION AND CONCLUSIONS}

The observations of the present research are in line with the past experience of farmers in the Traver area.

It is clear from the photographs of Figures 1 and 2 and from the rice yields that nonsaline sodic soils of the Fresno series which will not support the economic growth of cotton will nonetheless produce profitable yields of rice. At the same time, it is evident from the observations of plot number 4 that soil conditions exist in this area that will not permit even the growth of rice, at least during the first season.

Except for plot number 1, which showed a fair growth of cotton in the 1953 season and a good yield of rice in the 1954 season, the greenhouse tests indicate a considerable improvement in the productivity of the soils as a result of the rice culture. In the case of plot number 4 this fact is further substantiated by the growth of rice in the second season (Figure 4).

In certain respects, the chemical analyses are consistent with the yield data; in other respects, the two sets of information are disturbingly at variance. The data for plot number 1 shown in Table 3 are a case in point. It will be remembered that this plot yielded a fair crop of cotton and subsequently a good crop of rice (2,975 pounds of grain per acre). Also, the greenhouse tests on the surface soil indicated essentially the same productivity before and after rice culture. 
TABLE 3

EFFECT OF RICE CULTURE ON SURFACE SOIL (0-6") FROM OLIVER PLOT NO. 1

(All soil analyses are on the basis of the oven-dry soil $\left(105^{\circ} \mathrm{C}\right)$.)

\begin{tabular}{|c|c|c|}
\hline Item & Before rice & After rice \\
\hline Saturation moisture percentage $\ldots \ldots \ldots \ldots$ & 19.3 & 26.3 \\
\hline Conductivity sat. extract, mmhos per $\mathbf{c m} \ldots \ldots \ldots \ldots \ldots$ & 1.24 & 4.07 \\
\hline pH sat. extract....................... & 8.3 & 7.8 \\
\hline $\mathrm{Na}^{+}$, m.e./l. sat. extract. ..................... & 13.4 & 60.5 \\
\hline $\mathrm{Ca}^{++}+\mathrm{Mg}^{++}$, m.e./l. sat. extract..... & 2.10 & 5.10 \\
\hline Cation exchange capacity $\left(\mathrm{NH}_{4} \mathrm{Ac}\right)$, m.e. per 100 grams. & 5.7 & 6.1 \\
\hline Cation exchange capacity (NaAc), m.e. per 100 grams. & 5.5 & 6.6 \\
\hline Cation exchange capacity $(\mathrm{Ba})$, m.e per 100 grams. . & 5.1 & 5.5 \\
\hline Total extractable $\mathrm{Na}\left(\mathrm{NH}_{4} \mathrm{Ac}\right)$, m.e. per 100 grams... & 3.9 & 5.0 \\
\hline 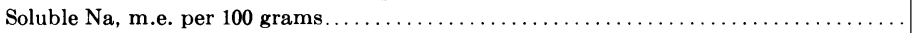 & 0.26 & 1.6 \\
\hline Exchangeable $\mathrm{Na}$, m.e. per 100 grams. & 3.6 & 3.4 \\
\hline Exchangeable $\mathrm{Na}$ percentage $\ldots . . . \ldots$ & 63 & 56 \\
\hline Gypsum requirement, m.e. per 100 grams....... & 0.83 & 1.5 \\
\hline
\end{tabular}

Yield of rice $=2,975$ lbs grain per acre.

TABLE 4

EFFECT OF RICE CULTURE ON SURFACE SOIL $(0-6 ")$ FROM OLIVER PLOT NO. 2

(All soil analyses are on the basis of the oven-dry soil $\left(105^{\circ} \mathrm{C}\right)$.)

\begin{tabular}{|c|c|c|}
\hline Item & Before rice & After rice \\
\hline Saturation moisture percentage ......... & 23.3 & 21.6 \\
\hline Conductivity sat. extract, $\mathrm{mmhos}$ per $\mathrm{cm} . .$. & 2.03 & 3.20 \\
\hline $\mathrm{pH}$ sat. extract. $\ldots \ldots \ldots \ldots \ldots \ldots \ldots \ldots$ & 8.3 & 6.8 \\
\hline $\mathrm{Na}^{+}$, m.e./l. sat. extract. $\ldots \ldots \ldots \ldots \ldots \ldots$ & 31.0 & 43.4 \\
\hline $\mathrm{Ca}^{++}+\mathrm{Mg}^{++}$, m.e./l. sat. extract...... & 1.30 & 27.4 \\
\hline Cation exchange capacity $\left(\mathrm{NH}_{4} \mathrm{Ac}\right)$, m.e. per 100 grams. & 6.8 & 5.4 \\
\hline Cation exchange capacity ( $\mathrm{NaAc}$ ), m.e. per 100 grams. . & 7.5 & 5.5 \\
\hline Cation exchange capacity $(\mathrm{Ba})$, m.e. per 100 grams.... & 6.3 & 4.5 \\
\hline Total extractable $\mathrm{Na}\left(\mathrm{NH}_{4} \mathrm{Ac}\right)$, m.e. per 100 grams. & 5.7 & 3.4 \\
\hline Soluble Na, m.e. per 100 grams................. & 0.72 & 0.94 \\
\hline Exchangeable $\mathrm{Na}, \mathrm{m} . e$. per 100 grams.......... & 5.0 & 2.5 \\
\hline Exchangeable $\mathrm{Na}$ percentage $\ldots \ldots \ldots \ldots \ldots$ & 74 & 46 \\
\hline Gypsum requirement, m.e. per 100 grams.. & 2.58 & 0.33 \\
\hline
\end{tabular}

Yield of rice $=2,325 \mathrm{lbs}$ grain per acre.

The conductivity data for plot number 1 show an important increase in the salinity of the surface soil as a result of the rice culture (from 1.24 to $4.07 \mathrm{mmhos}$ per $\mathrm{cm}$ in the saturation extract). Since this profile was initially nonsaline (conductivity of the saturation extract less than $1.5 \mathrm{~m}$. mhos per $\mathrm{cm}$ to a depth of at least 30 inches), this was probably due to salt carried in by the water from adjacent saline areas.

The analyses also show an increase in the proportion of $\mathrm{Na}^{+}$to $\mathrm{Ca}^{++}$in the saturation extract. Theoretically, this would indicate an increase in 
the exchangeable sodium percentage. The appreciable increase in the gypsum requirement value (from 0.83 to 1.5 ) is in harmony with this possibility. On the other hand, the determined exchangeable sodium percentage shows essentially no change as a result of the growth of rice. The exchangeable sodium percentage, however, is quite high $(\sim 60)$ - much higher than would be expected in a productive soil.

Although the data for plot number 2 (Table 4) show a small increase in conductivity following rice culture, there was a marked decrease in the proportion of $\mathrm{Na}^{+}$to $\mathrm{Ca}^{++}$in the saturation extract. Also there was a large decrease in the gypsum requirement value and a fair decrease in the ex-

TABLE 5

EFFECT OF RICE CULTURE ON SURFACE SOIL (0-6") FR.OM OLIVER PLOT NO. 3

(All soil analyses are on the basis of the oven-dry soil $\left(105^{\circ} \mathrm{C}\right)$.)

\begin{tabular}{|c|c|c|}
\hline Item & Before rice & After rice \\
\hline 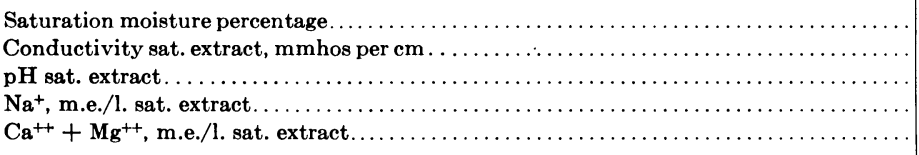 & $\begin{array}{l}28.8 \\
3.16 \\
8.4 \\
44.0 \\
1.60\end{array}$ & $\begin{array}{l}28.8 \\
2.54 \\
7.6 \\
34.4 \\
4.45\end{array}$ \\
\hline 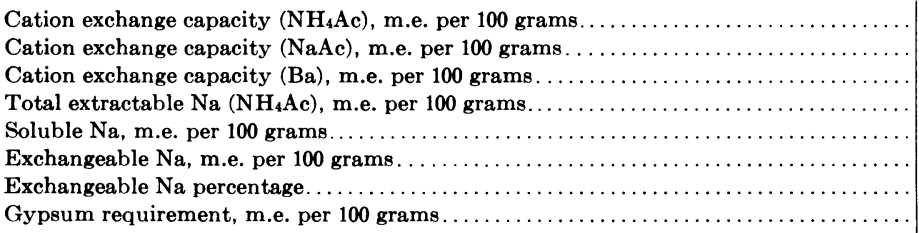 & $\begin{array}{r}10.1 \\
10.0 \\
9.7 \\
8.9 \\
1.3 \\
7.6 \\
75 \\
4.48\end{array}$ & $\begin{array}{r}9.4 \\
8.8 \\
8.7 \\
6.7 \\
1.0 \\
5.7 \\
61 \\
1.53\end{array}$ \\
\hline
\end{tabular}

Yield of rice $=3,025$ lbs grain per acre.

changeable sodium percentage. These results are consistent with the fact that the greenhouse test showed a marked improvement of this soil after the growth of rice. The exchangeable sodium percentage is still high, however, and one would not expect a good yield of rice at this level.

In most respects, the data for plot number 3 (Table 5) support the conclusion from the greenhouse tests that the rice culture has markedly increased the productivity of the surface soil. There was a decrease in the salinity and the proportion of $\mathrm{Na}^{+}$to $\mathrm{Ca}^{++}$in the saturation extract. Also, there were important decreases in the gypsum requirement value and the exchangeable sodium percentage. Here again, however, the exchangeable sodium percentage appears high (75 per cent-61 per cent) and one certainly would not expect a rice yield of 3,025 pounds of grain per acre on this basis.

As may be seen from Table 6, plot number 4 differed from the other three plots in that it was initially saline (conductivity of the saturation extract $8.41 \mathrm{mmhos}$ per $\mathrm{cm}$ ). Moreover, the table shows that the salt was effectively removed from the surface soil during the flooding period. Also, 
the ponding brought about a marked reduction in the proportion of $\mathrm{Na}^{+}$to $\mathrm{Ca}^{++}$in the saturation extract as well as reductions in the gypsum requirement value and the exchangeable sodium percentage.

The initial exchangeable sodium percentage in plot number 4 had the impossible value of 130 . Moreover, the final value of 95 is certainly inconsistent with the facts that bean plants were able to survive in this soil in the greenhouse (see Figure 3) and a certain amount of rice grew on this plot during the second season (see Figure 4). It seems clear that the accepted method for the determination of exchangeable sodium percentage is subject to large error with this type of soil.

TABLE 6

EFFECT OF RICE CULTURE ON SURFACE SOIL

(0-6") FROM OLIVER PLOT NO. 4

(All soil analyses are on the basis of the oven-dry soil $\left(105^{\circ} \mathrm{C}\right)$.)

\begin{tabular}{|c|c|c|}
\hline Item & Before rice & After rice \\
\hline Saturation moisture percentage. & 30.5 & 25.2 \\
\hline Conductivity sat. extract, mmhos per $\mathrm{cm}$. & 8.41 & 2.38 \\
\hline pH sat. extract....................... & 9.5 & 8.4 \\
\hline $\mathrm{Na}^{+}$, m.e./l. sat. extract.......... & 143 & 29.4 \\
\hline $\mathrm{Ca}^{++}+\mathrm{Mg}^{++}$, m.e./l. sat. extract.... & 1.00 & 0.80 \\
\hline Cation exchange capacity $\left(\mathrm{NH}_{4} \mathrm{Ac}\right)$, m.e. per 100 grams.. & 8.1 & 7.8 \\
\hline Cation exchange capacity ( $\mathrm{NaAc})$, m.e. per 100 grams... & 8.0 & 7.6 \\
\hline Cation exchange capacity $(\mathrm{Ba})$, m.e. per 100 grams.... & 6.3 & 6.5 \\
\hline Total extractable $\mathrm{Na}\left(\mathrm{NH}_{4} \mathrm{Ac}\right)$, m.e. per 100 grams.... & 14.9 & 8.1 \\
\hline Soluble Na, m.e. per 100 grams.................. & 4.4 & 0.74 \\
\hline Exchangeable $\mathrm{Na}$, m.e. per 100 grams. . & 10.5 & 7.4 \\
\hline Exchangeable Na percentage.............. & 130 & 95 \\
\hline Gypsum requirement, m.e. per 100 grams........ & 5.48 & 2.58 \\
\hline
\end{tabular}

Yield of rice $=\mathbf{0}$.

In general, the $\mathrm{NH}_{4} \mathrm{Ac}$ and the $\mathrm{NaAc}$ methods for the determination of cation exchange capacity have shown good agreement in this research. There has been a tendency for the Ba method to give somewhat lower results. At any rate, it appears unlikely that the unreasonably high values for the exchangeable sodium percentage are the result of low values for the cation exchange capacity.

At the present time, the most reasonable conclusion is that the determined value for exchangeable plus soluble sodium is largely in error and too high. Evidently there are sodium compounds or minerals present in this soil which are insoluble in the saturation water but which are solubilized or decomposed by the extraction with neutral normal ammonium acetate. This aspect is currently being investigated.

Unpublished analyses of a number of other sodic soils indicate that this difficulty in determining the exchangeable sodium percentage may be far more general than previously realized.

Certainly with this soil, the assumption that the gypsum requirement value is equivalent to the correct value for the exchangeable sodium would 
lead to much more reasonable levels for the exchangeable sodium percentage. However, this assumption requires separate verification. Also, in the authors' experience, the correlation between the gypsum requirement and the exchangeable sodium values is not good for sodic soils in general.

In conclusion, it can be said that the results of the present research constitute additional support for the use of rice culture in reclaiming soils of the Fresno series. At the same time, they point up the fact that our present methods of chemical examination fall woefully short of assessing the productivity of salt-affected soils.

\section{LITERATURE CITED}

Bower, C.A., R. F. Reitemeite, and M. Fireman

1952. Exchangeable cation analysis of saline and alkali soils. Soil Science 73:251-61.

Kelley, W. P.

1951. Alkali soils; their formation, properties, and reclamation. vi +176 pp. Reinhold Publishing Corporation, New York, N. Y.

Overstreet, Roy, J. C. Martin, and H. M. King

1951. Gypsum sulfur, and sulfuric acid for reclaiming an alkali soil of the Fresno series. Hilgardia 21 (5) :113-27.

Overstreet, Roy, J. C. Martin, R. K. Schulz, and O. D. McCutcheon

1955. Reclamation of an alkali soil of the Hacienda series. Hilgardia 24 (3) :53-68.

Schoonover, W. R.

1952. Examination of soils for alkali. University of California Extension Service. Berkeley, California. (Mimeo.)

1955. Cation exchange capacity by barium saturation and replacement with saturated gypsum solution. University of California Extension Service, Berkeley, California. (Unpublished) 


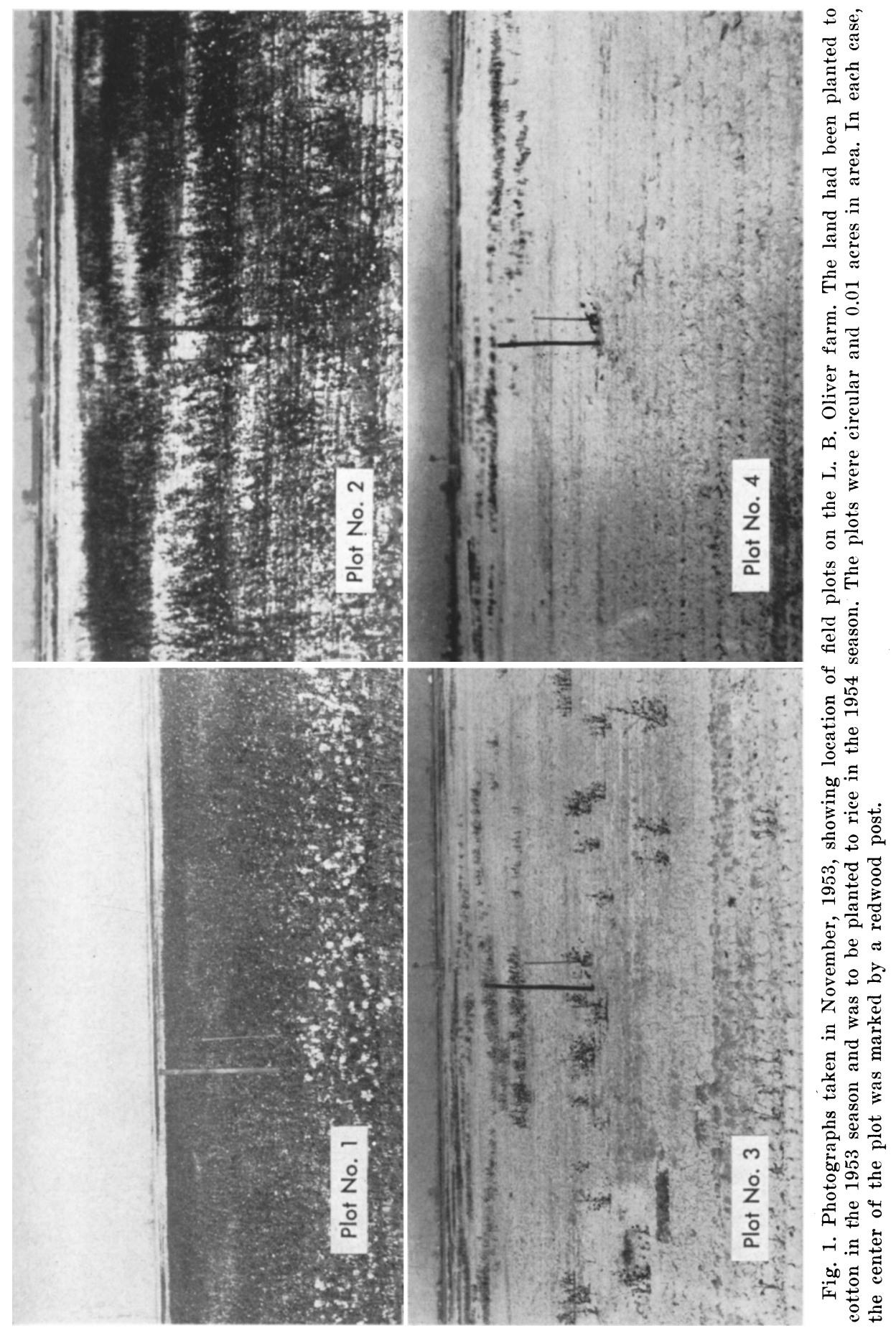




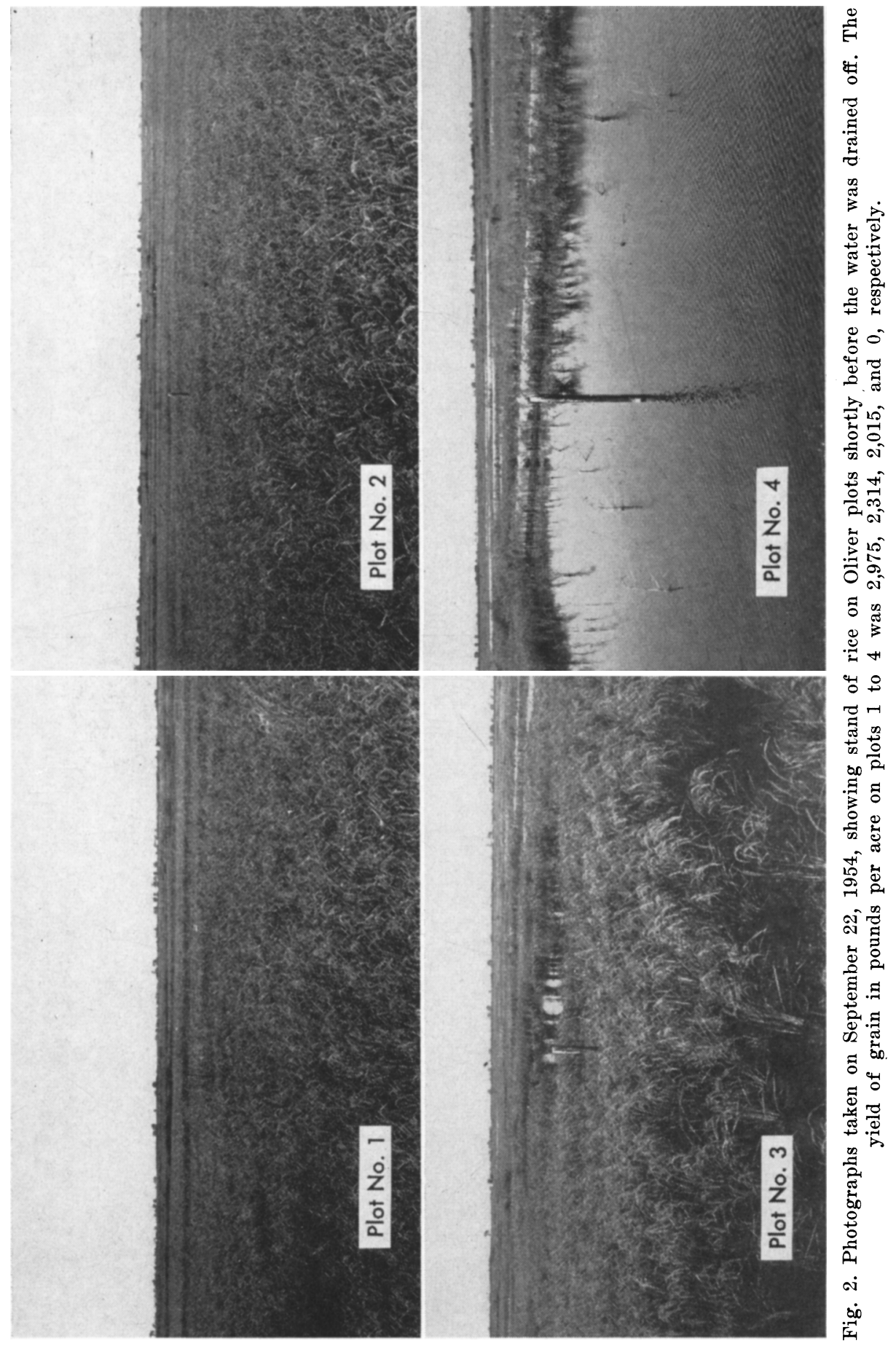



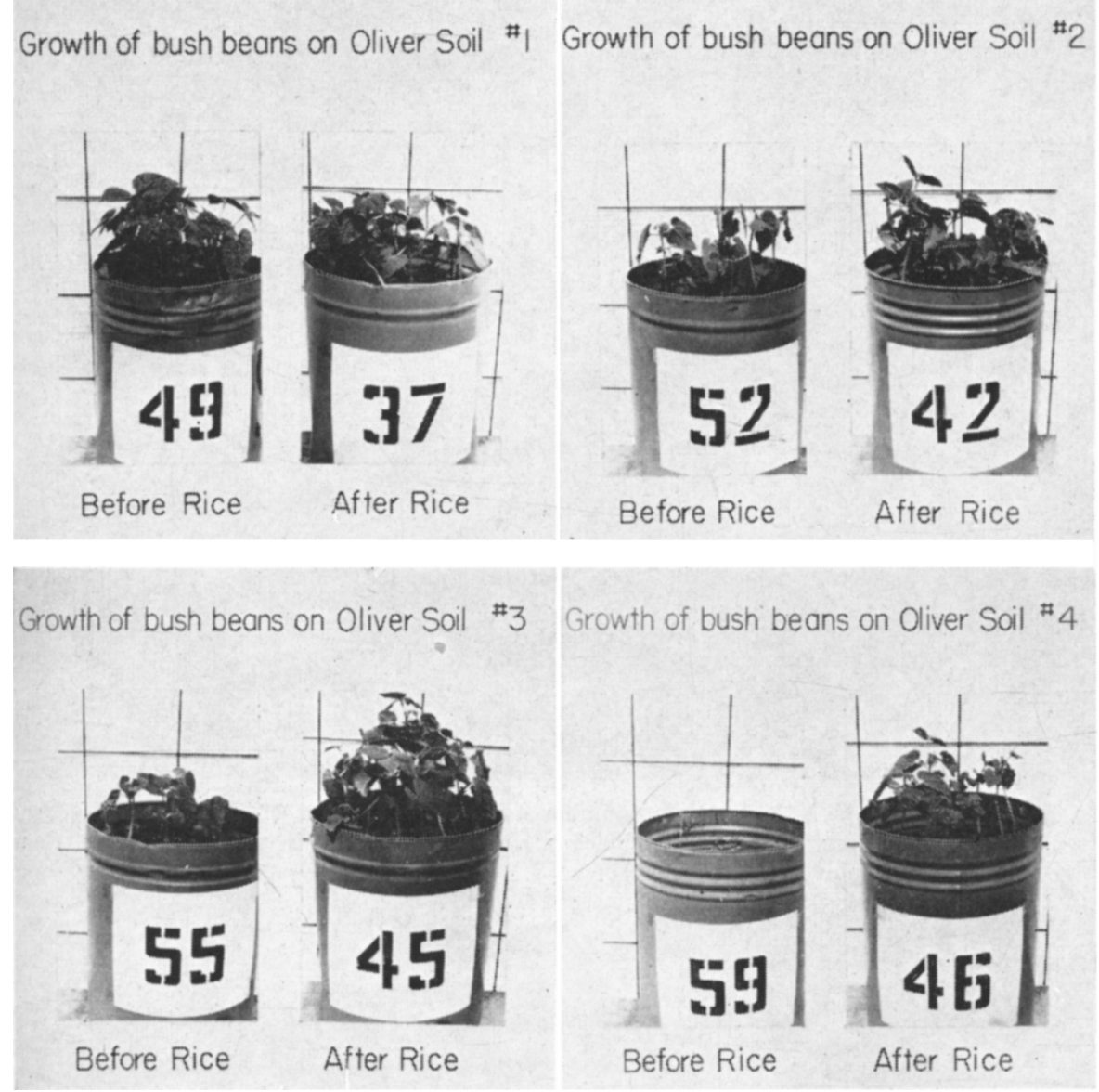

Fig. 3. Photographs showing the growth of bush beans on surface soils (0-6") from Oliver plots before and after rice culture. The photographs were taken in June, 1955, eight weeks after the time of planting. Each test was run in triplicate and at this time the average fresh weights of the tops before and after rice culture were as follows: plot number 1, $55.6 \mathrm{gm}$ and $47.6 \mathrm{gm}$; plot 2, $20.1 \mathrm{gm}$ and $97.9 \mathrm{gm}$; plot number $3,3.6 \mathrm{gm}$ and $55.6 \mathrm{gm}$; and plot number $4,1.7 \mathrm{gm}$ and $27.3 \mathrm{gm}$. 


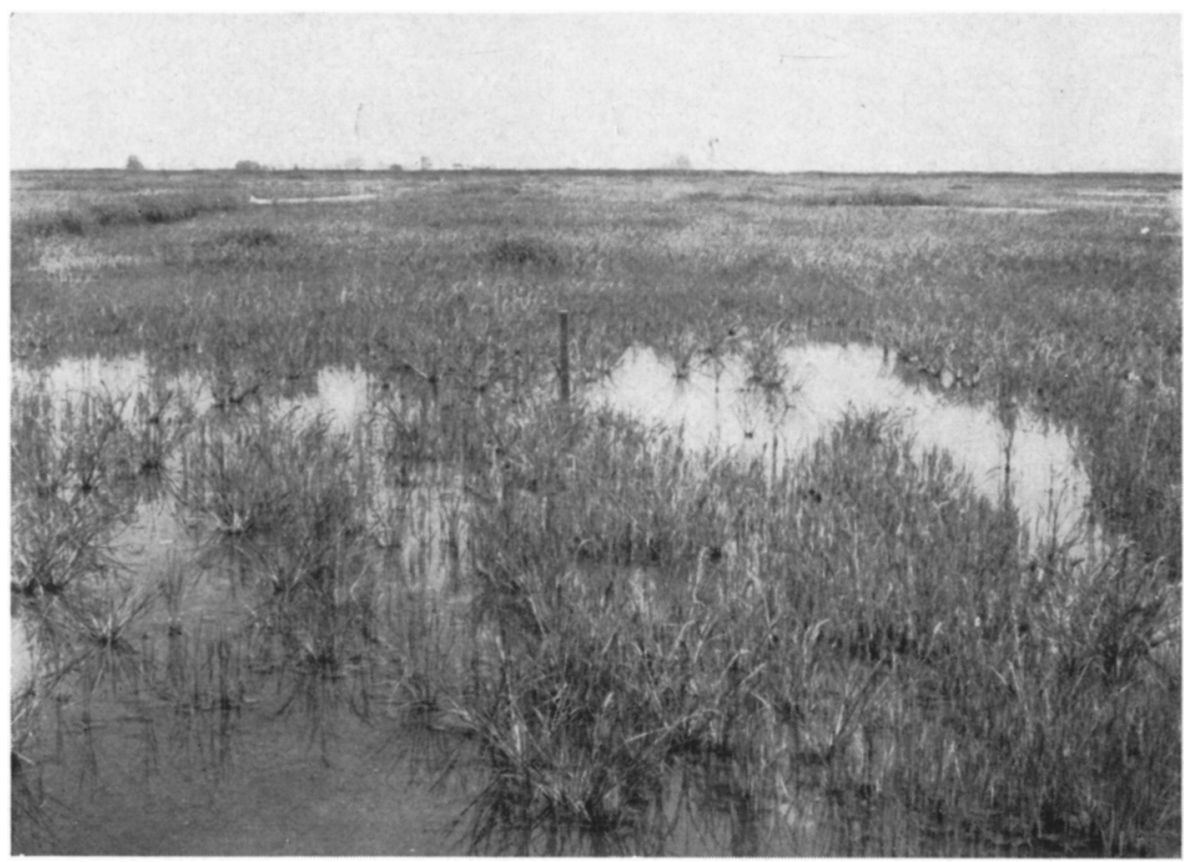

Fig. 4. Photograph of Oliver plot number 4 taken on August 12, 1955, in the second season of rice culture. This plot produced a zero yield of rice in the first season. Compare with figure 2 , plot 4 . 
The journal Hilgardia is published at irregular intervals in volumes of about 600 pages. The number of issues per volume varies. Subscriptions are not sold. The periodical is sent as published only to libraries, or to institutions in foreign countries having publications to offer in exchange.

You may obtain a single copy of any issue free, as long as the supply lasts; please request by volume and issue number from:

Agricultural Publications

Room 22, Giannini Hall

University of California

Berkeley 4, California

The limit to nonresidents of California is 10 separate issues on a single order. A list of the issues still available will be sent on request. 


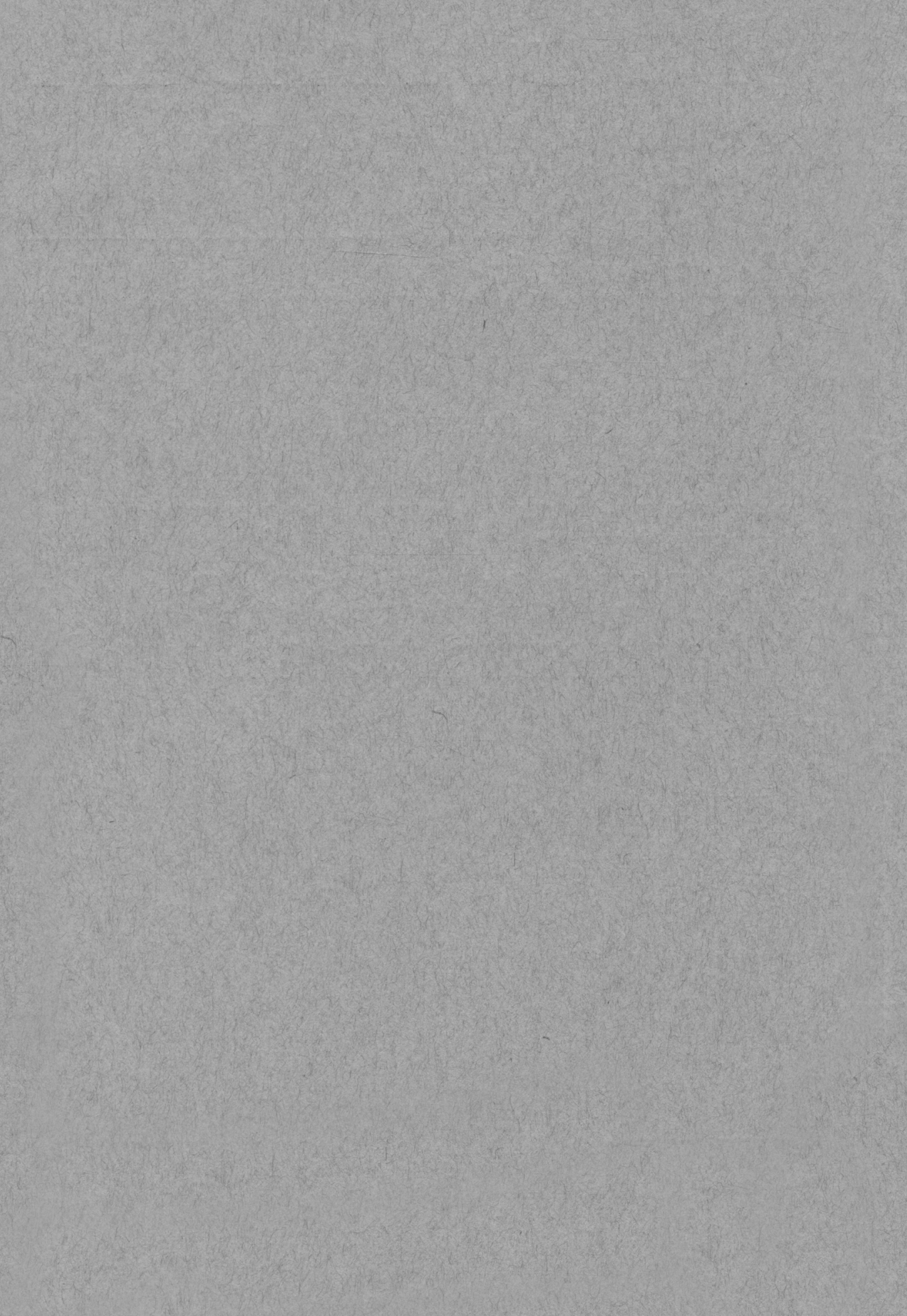

